\title{
Экономические последствия
}

\section{развития угледобывающей отрасли региона: оценка эколого-экономических потерь}

DOI: http://dx.doi.org/10.18796/0041-5790-2021-11-19-24

Статья посвящена исследованию проблем развития угледобывающей отрасли региона и оценке экологоэкономических потерь, обусловленных ее деятельностью. Выявлено, что интенсивное развитие угледобывающей промышленности сопровождается негативными экологическими последствиями, связанными с воздействием на социально-экономическое развитие и качество жизни населения региона. Для анализа и оценки экологоэкономических потерь для экономики региона предложена методика оценки потерь валового регионального продукта (потери ВРП), связанного с потерями рабочего времени вследствие заболеваемости населения, определяемыми уровнем загрязнения окружающей среды. Разработанная методика решает задачу оценки влияния экологической компоненты не только на эколого-экономические потери, характеризующиеся потерями ВРП, но и на качество жизни населения. Кроме того, регрессионный характер модели позволяет выявить экономический потенциал деятельности производителей и объективную эффективность предприятий, что позволит осуществлять возмещение потерь, наносимых загрязнением природной среды, адекватное негативным последствиям деятельности этих предприятий. Ключевые слова: экономика региона, угледобывающая отрасль, загрязняющие вещества, антропогенная нагрузка, среда обитания, здоровье населения, демографическая ситуация, потери ВРП, качество жизни.

Для цитирования: Экономические последствия развития угледобывающей отрасли региона: оценка экологоэкономических потерь / В.В. Меркурьев, П.Д. Косинский, К.В. Томилин и др. // Уголь. 2021. № 11. С. 19-24. DOI: 10.18796/0041-5790-2021-11-19-24.

\section{ВВЕДЕНИЕ}

Современное развитие экономики характеризуется высокими темпами развития угледобывающей промышленности, способствующими экологической деградации в некоторых регионах страны. Негативные экологические последствия становятся объектом пристального внимания ученых и практиков. Сложившаяся ситуация показывает определенную непоследовательность в отношении того, как оцениваются использование природных ресурсов и их потери, воздействие в связи с этим на окружающую сре-

\section{MEPКУРЬEВ В.B.}

Канд. экон. наук, доцент, заведующий кафедрой Теории и технологий управления КузГТУ, 650056, г. Кемерово, Россия, e-mail:merkurevvv@kuzstu.ru

\section{коСИнСКИй п.д.}

Доктор экон. наук, профессор, профессор кафедры Государственного и муниципального управления КузГту, 650056, г. Кемерово, Россия, e-mail:krishtof1948@mail.ru

\section{томилин К.В.}

Старший преподаватель кафедры

Теории и технологий управления КузГТУ, 650056, г. Кемерово, Россия, e-mail:tkv.gmu@kuzstu.ru

\section{КОЛЕСНИКОВА Е.Г.}

Канд. экон. наук, дочент, дочент кафедры Региональной и отраслевой экономики КемГУ, 650000, г. Кемерово, Россия, e-mail: elenakolesnikova39@gmail.com 
ду, нанесение экономике страны и отдельным ее регионам эколого-экономических потерь. Недооценка экологоэкономических потерь искажает показатели развития экономики, что не позволяет правильно выбрать эффективное социально-экономическое направление в целом.

Отсутствие совершенных методик оценки экологоэкономических потерь для экономики не позволяет с высокой степенью достоверности оценить последствия развития угольной промышленности и обосновать необходимость ввода экологической компоненты в контекст социально-экономического развития, направленного на повышение качества жизни и благосостояния людей. Особенно это важно для регионов, в которых присутствуют угледобывающая, металлургическая, химическая отрасли экономики, что влечет за собой наличие значительных площадей нарушенных земель. К таким регионам СФО, имеющим сырьевую специализацию, в полной мере относится Кемеровская область.

В области более половины ВРП формируется за счет угольной промышленности, представляющей собой ведущую отрасль региональной экономики. Поэтому разработка методики оценки эколого-экономических потерь от интенсивного развития угольной промышленности, позволяющей своевременно и эффективно принимать меры со стороны органов государственной власти, является актуальным вопросом.

\section{ЭКОЛОГО-ЭКОНОМИЧЕСКИЕ ПРОБЛЕМЫ В КУЗБАССЕ}

Угледобывающая отрасль, включающая многочисленные предприятия с открытой добычей угля, занимает большие площади земель региона и «...является источником отрицательного воздействия на окружаюшую среду посредством загрязнения атмосферного воздуха, водныхресурсов, содействует деградации пахотных земель, включая складирование горной породы на них» $[1,2,3,4,5]$. Ежегодное наращивание объемов добычи угля сопровождается увеличением изъятия сельскохозяйственных земель, в большинстве случаев имеющих высокие плодородные показатели.

Как отмечают А.И. Копытов, А.Н. Куприянов: «Негативной стороной текущей модели развития угольной отрасли Кузбасса и наращивания открытой добычи угля является увеличение площади нарушенных земель, при котором изменяется общий профиль земной поверхности, полностью или частично уничтожается биологическое разнообразие» [6].

Специалисты считают, что добыча каждого миллиона тонн угля сопровождается нарушением 10 га земли. Следует подчеркнуть, что открытым способом добывается около 60\% угля в регионе. За анализируемый период (2016-2020 гг.) площади нарушенных земель увеличились на 7,77\%, с 73,3 тыс. га до 97,6 тыс. га [7]. Нормативная стоимость введения в оборот земель несельскохозяйственного назначения в 2014 г. составляла 1020 тыс. руб. на один га.

На протяжении многих десятилетий считалось возможным восстановить утраченное плодородие отвалов в быстром периоде времени и оправдать средства, затраченные на работы, связанные с биологической рекультивацией. Но, как показывает действительность, в регионе нет примеров, когда рекультивированные земли используют- ся в целях сельскохозяйственного производства или лесохозяйственных целях [8].

Добыча угля подземным способом сопровождается обустройством площадок для складирования угля и горной породы, технологии вентиляции подземных выработок, проветривания и дегазации, способствует поступлению в атмосферу метана, что представляет собой основные источники загрязнения атмосферного воздуха. Порода, выдаваемая из шахт содержит значительное количество угля. При ее складировании уголь при взаимодействии с атмосферой самовозгорается, выделяя при этом сернистый газ, смолистые вещества в виде продуктов возгонки, окись углерода.

Технологии проведения открытых горных работ предусматривают буровзрывные работы, сопровождающиеся газопылеобразованием, являющимся загрязнителем атмосферного воздуха. Высокоинтенсивная добыча угля в регионе сопровождается наличием признаков деградации земель, включая их плодородие, снижением популяции животных, а значит, потерей возобновляемых природных ресурсов. При этом интенсивное развитие угольной промышленности увеличивает выбросы летучих веществ в атмосферу и загрязняет воздушную среду $[9,10,11,12,13]$.

Объемы добычи угля в 2020 г. составили 220,7 млн т, на 11,8\% меньше аналогичного периода 2019 г. (250,1 млн т), по данным Министерства угольной промышленности Кузбасса. Интенсивная добыча угля с применением открытого способа сопровождается загрязнением атмосферы. За 2020 г. объемы выбросов веществ, загрязняющих атмосферный воздух превысили 1600 тыс. т (602 кг на одного жителя).

Типы различных загрязняющих веществ, попадающих в атмосферный воздух, превышают 250 единиц, различного рода опасности: «Среди них высокотоксичные и канцерогенные вещества в виде сажи, свинца, оксидов углерода и азота. Структура загрязняющих веществ в наибольшей степени содержит элементы, которые производятся стационарными источниками и являются твердыми веществами, объемом 146,8 тыс. т. Кроме того, объемыгазообразныхижидкихвеществ занимают 1340,8 тыс. m» [14].

Не менее серьезной проблемой является наличие метана и его выбросов, Наиболее перспективным направлением решения данной проблемы видится как использование метана на топливо, что позволит существенно сократить выбросы в атмосферу загрязняющих веществ. Современная региональная экономическая политика направлена на использование природно-ресурсных запасов, позволяющих динамично развиваться таким отраслям, как угольная и металлургическая. Для развития региональной экономики, обеспечения реализации социальных программ и стабильного социального развития такой подход вполне оправдан.

Однако это не решает проблемы улучшения здоровья населения как одной из важнейших составляющих качества жизни, представляющего собой основной индикатор социально-экономического положения страны и отдельных ее регионов. Среда обитания и ее качество характеризуются здоровьем населения, а динамика заболеваемости и смертность людей в трудоспособном возрасте показывают благополучие и отрицательные явления реги- 
Таблица 1

Показатели численности и процесса воспроизводства населения Кузбасса в 2016-2020 гг.

\begin{tabular}{|l|c|c|c|c|c|c|}
\hline \multicolumn{1}{|c|}{ Показатели } & $\mathbf{2 0 1 6}$ r. & $\mathbf{2 0 1 7}$ г. & $\mathbf{2 0 1 8}$ г. & $\mathbf{2 0 1 9}$ г. & $\mathbf{2 0 2 0}$ г. \\
\hline Население, на начало года, тыс. чел. & 2708,8 & 2694,8 & 2694,8 & 2674,3 & 2657,8 \\
\hline Родившихся (на 1000 населения) & 12,1 & 10,5 & 9,9 & 9,0 & 8,5 \\
\hline Умерших (на 1000 населения) & 14,3 & 14,1 & 14,4 & 14,2 & 16,1 \\
\hline Умерших в возрасте до 1 года (на 1000 населения) & 7,3 & 6,9 & 6,4 & 6,0 & 5,6 \\
\hline Естественная убыль населения (на 1000 чел.) & $-2,2$ & $-3,6$ & $-4,5$ & $-5,2$ & $-7,6$ \\
\hline Ожидаемая продолжительность жизни при рождении, лет & 68,72 & 69,35 & 69,32 & 69,78 & 68,5 \\
\hline
\end{tabular}

онального развития. Для Кемеровской области эти показатели являются основными проблемами. Воспроизводство населения имеет отрицательную динамику. Показатели, характеризующие процесс воспроизводства населения Кузбасса в 2016-2020 гг., представлены в табл. 1.

Сокращение населения Кузбасса за период 2016-2020 гг. составило 1,9\% (51,0 тыс. чел.). Темпы рождаемости упали на 29,7\% при резком росте смертности, которая в 2020 г. достигла показателя 16,1 (на 12,6\% к 2016 г.) [14]. При явных положительных тенденциях смертности детей до одного года демографическая ситуация выглядит неблагоприятной. Кемеровская область по плотности населения является одной из лидирующих в Сибирском федеральном округе - 27,77 в 2020 г. По этому показателю в 2020 г. Кузбасс занимал седьмое место в России и первое место в Сибирском федеральном округе.

Что касается здоровья и продолжительности жизни населения в регионе, то в демографическом рейтинге регионов - 2021 эксперты агентства РИА Рейтинг определили Кузбассу одно из последних мест. По естественной убыли населения Кузбасс занимает 80-е место среди субъектов РФ: в 2018-2020 гг. показатель составил -46,2 тыс. чел., миграционное сальдо также имеет отрицательное значение $-14,7$ тыс. чел. 50\% в структуре умершего населения - это граждане в трудоспособном возрасте, из них 78\% составляют мужчины [15].

Как и в большинстве регионов страны, демографическую ситуацию можно охарактеризовать сокращением численности населения вследствие невысокой продолжительности жизни и сокращения миграционного прироста. В 2020 г. миграционная убыль в Кемеровской области составила 3754 чел. Следствием негативного воздействия неблагоприятной окружающей среды на демографическую ситуацию в регионе являются повышенный уровень заболеваний органов дыхания, наличия новообразований, инфекционных и паразитарных заболеваний, травм, как производственных, так и бытовых несчастных случаев [13, 14].

Данные ГБУЗ «КОМИАЦ» свидетельствуют о снижении общей заболеваемости населения на 8,6\% к 2016 г., одновременно произошло увеличение среднегодового количества человеко-дней по болезни на 12,6\%. В 2020 г. отмечается превышение смертности над рождаемостью на 20,5 тыс. чел., почти в два раза. Младенческая смертность (детей в возрасте до 1 года на 1000 населения) имеет тенденцию к снижению. Однако она остается достаточно высоким показателем в силу предградиентного роста заболеваний и ряда патологий, обусловленных токсическими воздействиями химических соединений, находящихся в атмосферном воздухе, водоемах и в целом в окружающей среде, на организм матери и плода.
Подводя итог вышеизложенного, сделаем вывод, что неблагоприятные факторы окружающей среды оказывают существенное воздействие на здоровье, отражающееся на качестве жизни людей, а реальное улучшение экологической обстановки не отмечается.

\section{МЕТОДИКА ОЦЕНКИ ЭКОЛОГО-ЭКОНОМИЧЕСКИХ ПОТЕРЬ \\ ДЛЯ ЭКОНОМИКИ РЕГИОНА (ПОТЕРИ ВРП)}

В данном исследовании представляется целесообразным для оценки влияния заболеваемости населения на конечный результат экономической деятельности региона (ВРП) использовать методы эконометрики: корреляционный и регрессионный анализы.

Любое оценивание предполагает выбор объекта оценки: в данном случае это экономика региона, представленная конечным результатом - ВРП. Экономика региона сформировалась при сочетании различных природных условий и факторов, создавших условия для экономической деятельности. Экономическая деятельность в итоге определила обстановку на территории с негативными и позитивными последствиями для состояния здоровья населения [18].

Смертность населения связана с заболеваемостью, которая является индикатором состояния здоровья населения, его трудовой активности. Учитывая вышесказанное, авторами была выдвинута гипотеза о том, что заболеваемость населения оказывает влияние на изменение объема ВРП. Для аналитической оценки связи в качестве результирующей переменной был выбран объем ВРП (млрд руб.), в качестве факторов, объясняющих изменение ВРП, - общее число заболеваний на 1000 чел. населения (ед.) и число дней по болезни в среднем за год (чел.-дни). Определен период наблюдения - 11 лет. Для моделирования связи факторов были выбраны показатели (табл. 2).

Факт существования связи между признаками и тесноту этой связи проверяют с помощью коэффициента корреляции:

$r_{y x 1}=0,03$ (коэффициент корреляции показывает, что связь между объемом ВРП и общим числом заболеваний на 1000 чел. населения не существует);

$r_{y x 2}=-0,62$ (коэффициент корреляции показывает, что связь между объемом ВРП и числом дней по болезни в среднем за год умеренная и обратная, то есть с увеличением количества дней временной нетрудоспособности объем ВРП сокращается).

Таким образом, из дальнейшего исследования исключили фактор «общее число заболеваний на 1000 чел. населения» (см. рисунок). 
Значения показателей (факторов), используемых при моделировании

\begin{tabular}{|c|c|c|c|}
\hline & $\mathbf{Y}$ & $x_{1}$ & $x_{2}$ \\
\hline Годы & $\begin{array}{c}\text { Объем ВРП, } \\
\text { млрд руб. }\end{array}$ & $\begin{array}{c}\text { Общее число } \\
\text { заболеваний } \\
\text { на } 1000 \text { чел. } \\
\text { населения, ед. }\end{array}$ & $\begin{array}{c}\text { Число дней по } \\
\text { болезни в среднем } \\
\text { за год, чел.-дни }\end{array}$ \\
\hline 2010 & 625,9 & 1502,9 & 15,1 \\
\hline 2011 & 751,2 & 1573 & 14,9 \\
\hline 2012 & 718,3 & 1568,7 & 14,7 \\
\hline 2013 & 667,9 & 1620 & 15,0 \\
\hline 2014 & 752 & 1576 & 14,8 \\
\hline 2015 & 843,3 & 1586 & 12,6 \\
\hline 2016 & 903,3 & 1596 & 12,7 \\
\hline 2017 & 1097,9 & 1645,4 & 12,7 \\
\hline 2018 & 1266,4 & 1585 & 13,5 \\
\hline 2019 & 1110,4 & 1572,5 & 13,3 \\
\hline 2020 & 1100,0 & 1459,7 & 14,3 \\
\hline
\end{tabular}

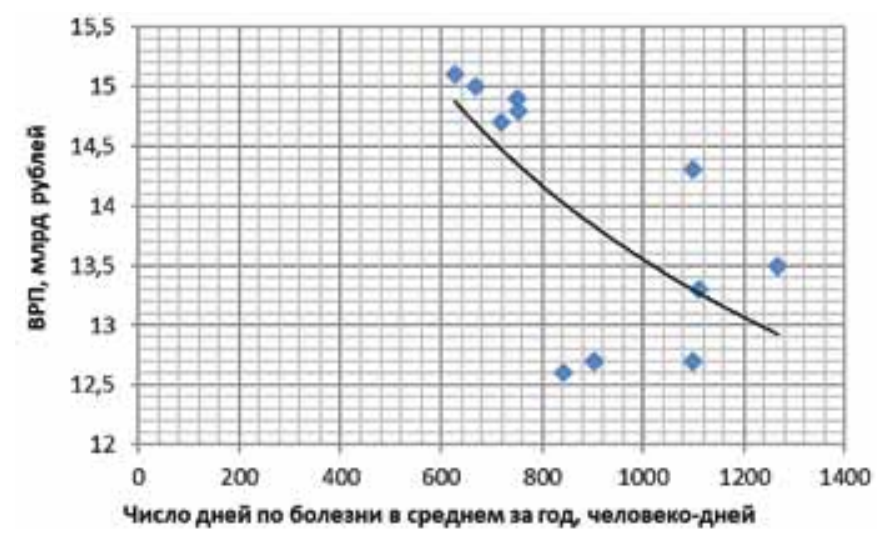

Поле корреляции между факторами «ВРП» u «Число дней по болезни в среднем за год»

Разброс точек более соответствует нелинейной связи. Поэтому для оценки используется уравнение степенной функции.

Полученная в ходе расчетов (с помощью пакета прикладных программ Stata.8) регрессионная статистика позволяет построить уравнение (регрессионную модель) следующего вида:

$$
y=e^{12,3} \cdot x^{-2,1}
$$

Экономическая интерпретация параметров модели:при увеличении количества дней по болезни в среднем за год на $1 \%$ объем ВРП будет снижаться в среднем на 2,1\%. Если 2,1\% представить в стоимостном выражении (используя показатель ВРП 2020 г.), то получится, что в среднем ежегодно экономика региона теряет 23,1 млрд руб. по причине временной нетрудоспособности населения.

Проверка качества модели:

- $R^{2}=0,42$ свидетельствует о том, что вариация зависимой переменной ВРП в среднем на $42 \%$ объясняется вариацией независимой переменной «Число дней по болезни в среднем за год», а необъясненная вариация на $58 \%$ зависит от факторов, не учтенных в регрессионной модели;
- проверка значимости модели с помощью критерия Фишера: $F_{\text {набл }}=6,55>F_{\text {табл }}=5,12$ убеждает в том, что построенное уравнение регрессии (1) значимо и его можно использовать в практике моделирования и прогнозирования.

Таким образом, выдвинутая авторами гипотеза о том, что заболеваемость населения оказывает влияние на изменение объема ВРП доказана.

Проведенное исследование еще раз подчеркивает специфические особенности экономики региона и убеждает в том, что законодательные меры в области охраны окружающей среды, экологизации производств и ответственности экономических агентов будут долго оставаться стратегическими экологическими задачами региона в условиях увеличения добычи угля и производства основных видов промышленной продукции.

\section{выводы}

Резюмируя вышеизложенное, можно сделать вывод о значительном уровне эколого-экономических потерь, наносимых экономике региона интенсивно развивающейся угольной промышленностью. К тому же, это создает ситуацию, характеризующуюся высокой антропогенной нагрузкой и уровнем заболевания людей, превышающим средний показатель в России более чем в два раза. Стоимостная оценка ущерба, обусловленного развитием угледобывающей отрасли региона, показывает рост в виде потерь ВРП, довольно высокой заболеваемости населения, ухудшения его здоровья и продолжительности жизни, снижения численности населения региона, что несет в себе высокие экономические риски не только в настоящее время, но и в будущем.

Поэтому первостепенной задачей государственной власти региона, на наш взгляд, является разработка и принятие незамедлительных решений, направленных на применение автоматизированных, объективных инструментов, позволяющих оценить и сбалансировать затраты на повышение экономической эффективности и сохранение окружающей среды региона. Данные решения должны включать увеличение инвестиций, направляемых на технологическую модернизацию морально устаревшего оборудования, и содержать обязательный элемент - безотходные технологии утилизации отходов.

Предлагаемая методика решает задачу оценки влияния экологической компоненты не только на экологоэкономические потери, характеризующиеся потерями ВРП, но и на качество жизни населения. Кроме того, регрессионный характер модели позволяет выявить экономический потенциал деятельности производителей и объективную эффективность предприятий, что позволит осуществлять адекватное негативным последствиям их деятельности возмещение потерь, получаемых от загрязнения природной среды. Предлагаемый методический подход к определению объема эколого-экономических потерь в регионе является универсальным, может применяться государственными органами власти при корректировке программ социально-экономического развития региона на перспективу и других регионов с аналогичным развитием экономики. 


\section{Список литературы}

1. Анализ экологических проблем в угледобывающих регионах / О.М. Зиновьева, Л.А. Колесникова, А.М. Меркулова и др. //Уголь. 2020. № 10. С. 62-67. DOI: 10.18796/00415790-2020-10-62-67.

2. Ларин Н.С., Казьмина О.Ю. Оценка влияния работы угольных разрезов на состояние окружающей среды. Перспективы инновационного развития угольных регионов России / Сборник трудов IV Международной научнопрактической конференции. Прокопьевск: Издательство филиала КузГТУ в г. Прокопьевске, 2014. 506 с.

3. Рыбак Л.В. Эколого-экономический анализ состояния окружающей среды урбанизированной территории Кузбасса. М.: МГГУ, 2009. 479 с.

4. Рожков А.А. Социально-экономические проблемы развития угольной отрасли и территорий ее промышленной дислокации (избранные труды). М.: ООО «Редакция журнала «Уголь», 2013. 426 с.

5. Brusseau M., Pepper I., Gerba C. Environmental and Pollution Science. Academic Press, 2019.662 p.

6. Копытов А.И., Куприянов А.Н. Новая стратегия развития угольной отрасли Кузбасса и решение экологических проблем // Уголь. 2019. № 11. C. 89-93. DOI: 10.18796/00415790-2019-11-89-93.

7. Доклад о состоянии окружающей среды Кемеровской области - Кузбасса в 2020 году. Кемерово: Администрация Правительства Кузбасса, Министерство природных ресурсов и экологии Кузбасса, 2021. 240 с.

8. Добыча угля в Кузбассе и новые технологии / А.И. Копытов, О.А. Куприянов, Ю.А. Манаков и др. // ЭКО. 2021. № 6(654). С. 67-76.

9. Ковалев В.А., Потапов В.П., Счастливцев Е.Л. Мониторинг состояния природной среды угледобывающих районов Кузбасса. Новосибирск: Издательство СО РАН, 2013. 312 с.
10. Sustein C.R. Two Conception of Irreversible Environmental harm // Law school the 13 University of Chicago. May 2008. N 407. P. 287.

11. Ecological management as a factor of mining region development / N. Egorova, N. Zaruba, T. Jurzina et al. / In the collection: E3S Web of Conferences. 3rd International Innovative Mining Symposium, IIMS 2018. Electronic edition, 2018.

12. Prospects for powering past coal / J. Jewell, V.Vinichenko, L. Nacke et al. // Nature Climate Change. 2019. Vol. 9.

13. Исследование основных показателей горно-экологоэкономической системы / В.Г. Михайлов, С.М. Бугрова, Ю.С. Якунина и др. // Уголь. 2019. № 9. С. 106-111. DOI: 10.18796/0041-5790-2019-9-106-111.

14. Территориальный орган Федеральной службы государственной статистики по Кемеровской области. [Электронный ресурс]. URL: http://www.kemerovostat.ru (дата обращения: 15.10.2021).

15. Демографический рейтинг регионов - 2021. РИА Рейтинг. [Электронный ресурс]. URL: https://riarating.ru/ infografika/20210405/630198230.html (дата обращения: 15.10.2021).

16. Косинский П.Д., Бондарев Н.С., Бондарева Г.С. Развитие сельских территорий горнодобывающего региона: проблемы и перспективы // АПК: экономика и управление. 2020. № 5. С. 79-87.

17. Lung cancer risk at low radon exposure rates in German uranium miners / M. Kreuzer, N. Fenske, M. Schnelzer et al. // British Journal of Cancer. 2015. Vol. 113. P. 1367-1369.

18. Колесникова Е.Г., Чекменева Т.Д. Оценка влияния результатов экономической деятельности на состояние окружающей среды региона // Вестник Кемеровского государственного университета. 2013. № 2-1 (54). С. 277-283.

Original Paper

ECONOMIC OF MINING

UDC 338.45:622.85:622.33(571.17) @ V.V. Merkuryev, P.D. Kosinsky, K.V. Tomilin, E.G. Kolesnikova, 2021 ISSN 0041-5790 (Print) • ISSN 2412-8333 (Online) • Ugol' - Russian Coal Journal, 2021, № 11, pp. 19-24 DOI: http://dx.doi.org/10.18796/0041-5790-2021-11-19-24

Title

ECONOMIC IMPACT OF THE COAL INDUSTRY IN THE REGION: ASSESSMENT OF ENVIRONMENTAL AND ECONOMIC LOSSES

\author{
Authors \\ Merkuryev V.V. ${ }^{1}$, Kosinsky P.D. ${ }^{1}$, Tomilin K.V. ${ }^{1}$, Kolesnikova E.G. ${ }^{2}$ \\ ${ }^{1}$ Gorbachev Kuzbass State Technical University (KuzSTU), Kemerovo, 650000, Russian Federation \\ ${ }^{2}$ Kemerovo State University, 650000, Kemerovo, Russian Federation
}

Authors Information

Merkuryev V.V., PhD (Economic), Associate Professor, Head of Theory and management technologies department, e-mail: merkurevvv@kuzstu.ru Kosinsky P.D., Doctor of Economic Sciences, Professor, Professor of State and municipal administration department, e-mail: krishtof1948@mail.ru Tomilin K.V., Senior Lecturer of Theory and management technologies department, e-mail: tkv.gmu@kuzstu.ru

Kolesnikova E.G., PhD (Economic), Associate Professor, Associate Professor of Regional and sectoral economics department,

e-mail: elenakolesnikova39@gmail.com

\section{Abstract}

The paper is devoted to the study of the problems of the development of the coal mining industry of the region and the assessment of environmental and economic losses due to its activities. It was revealed that the intensive development of the coal mining industry is accompanied by negative environmental consequences related to the impact of social and economic development and the quality of life of the population of the region. For the analysis and assessment of environmental-economic losses for the economy of the region, a methodology has been proposed for estimating (GRP loss) associated with losses of working time due to the incidence of the population determined by the level of environmental pollution. The developed methodology solves the task of assessing the impact of the environmental component not only of environmental and economic losses characterized by GRP losses, but also on the quality of life of the population. In addition, the regression nature of the model reveals the economic potential of producers and the objective efficiency of enterprises, which will allow adequate compensation for the negative consequences of their activities and losses caused by pollution of the natural environment. 


\section{Keywords}

Regional economy, Coal mining industry, Pollutants, Anthropogenic load Habitat, Population health, Demographic situation, GRP losses, Quality of life.

\section{References}

1. Zinovieva O.M., Kolesnikova L.A., Merkulova A.M. \& Smirnova N.A. Environmental analysis in coal mining regions. Ugol', 2020, (10), pp. 62-67. (In Russ.). DOI: 10.18796/0041-5790-2020-10-62-67.

2. Larin N.S. \& Kazmina O.Yu. Assessment of the impact of coal mine operations on the environment. Prospects for Innovative Development of Coal Regions of Russia / Collection of Works of the IV International Scientific and Practical Conference. Prokopyevsk, Branch of KuzSTU in Prokopyevsk Publ., 2014, 506 p. (In Russ.).

3. Rybak L.V. Ecological-economic analysis of the state of the environment of the urbanized territory of Kuzbass. Moscow, MSMU Publ., 2009, 479 p. (In Russ.).

4. Rozhkov A.A. Socio-economic problems of the development of the coal industry and the territories of its industrial deployment (selected works). Moscow, “Ugol' Journal Edition” LLC, 2013, 426 p. (In Russ.).

5. Brusseau M., Pepper I. \& Gerba C. Environmental and Pollution Science. Academic Press, 2019, 662 p.

6. Kopytov A.I. \& Kupriyanov A.N. A new strategy for the development of the coal industry of Kuzbass and solving environmental problems. Ugol', 2019, (11), pp. 89-93. (In Russ.). DOI: 10.18796/0041-5790-2019-11-89-93.

7. Report on the state of the environment of the Kemerovo Region - Kuzbass in 2020. Kemerovo, Administration of the Kuzbass Government, Ministry of Natural Resources and Ecology of Kuzbass, 2021, 240 p. (In Russ.).

8. Kopytov A.I., Kupriyanov O.A., Manakov Yu.A. \& Kupriyanov A.N. Coal mining in Kuzbass and new technologies. ECO, 2021, (6), pp. 67-76. (In Russ.).

9. Kovalev V.A., Potapov V.P. \& Schastlivtsev E.L. Monitoring the state of the natural environment of coal mining areas of Kuzbass. Novosibirsk, Publishing House SB RAS, 2013, 312 p. (In Russ.).

10. Sustein C.R. Two Conception of Irreversible Environmental harm. Law school the 13 University of Chicago, May 2008, (407), pp. 287.
11. Egorova N., Zaruba N., Jurzina T. et al. Ecological management as a factor of mining region development. In the collection: E3SWeb of Conferences, 3rd International Innovative Mining Symposium, IIMS 2018. Electronic edition, 2018. 12. Jewell J., Vinichenko V., Nacke L. et al.Prospects for powering past coal. Nature Climate Change, 2019, Vol. 9.

13. Mikhailov V.G., Bugrova S.M., Yakunina Ju.S., Muromtseva A.K. \& Mikhailova Ya.S. Study of the main indicators of the mining eco-economic system. Ugol', 2019, (9), pp. 106-111. (In Russ.). DOI: 10.18796/0041-5790-2019-9-106-111. 14. Territorial body of the Federal State Statistics Service for the Kemerovo Region. [Electronic resource]. Available at: http://www.kemerovostat.ru (accessed 15.10.2021). (In Russ.).

15. The demographic rating of the regions is 2021. RIA Rating. [Electronic resource]. Available at: https://riarating.ru/infografika/20210405/630198230. html (accessed 15.10.2021). (In Russ.).

16. Kosinsky P.D., Bondarev N.S. \& Bondareva G.S. Rural development of the mining region: challenges and prospects. AIC: economy and management, 2020, (5), pp. 79-87. (In Russ.).

17. Kreuzer M., Fenske N., Schnelzer M. et al. Lung cancer risk at low radon exposure rates in German uranium miners. British Journal of Cancer, 2015, Vol. 113(9), pp. 1367-1369.

18. Kolesnikova E.G. \& Chekmeneva T.D. Assessment of the impact of economic results on the environment of the region. Bulletin of Kemerovo State University, 2013, No. 2-1 (54), pp. 277-283. (In Russ.).

\section{For citation}

Merkuryev V.V., Kosinsky P.D., Tomilin K.V. \& Kolesnikova E.G. Economic impact of the coal industry in the region: assessment of environmental and economic losses. Ugol', 2021, (11), pp. 19-24. (In Russ.). DOI: 10.18796/00415790-2021-11-19-24.

\section{Paper info}

Received September 15, 2021

Reviewed October 12, 2021

Accepted October 15, 2021 